Europe's Journal of Psychology, 6(4), pp. 170-191

www.ejop.org

\title{
Women's subjective experiences of food and eating on the island of the 'Mediterranean diet'
}

\author{
Sofia Triliva \\ University of Crete
}

\begin{abstract}
The purpose of this research was to explore and develop an understanding of Cretan women's subjective experiences regarding food and eating behaviors. On average, 43 community group participants provided reflective written feedback after eleven consecutive meetings. The participants ranged in age from 20 to 85 years. The group engaged in experiential activities and critical reflection with the aim of construction and generation of meanings regarding women's subjective experiences of food, eating, nutrition and body image. The women expressed worry and confusion concerning what the 'right' foods are, and balancing 'tradition' with new and conflicting 'lifestyles'. Younger women were more concerned with diet and body image, middle age participants with preparing 'appropriate' foods for their families, and older participants with the changing practices in traditional cuisine. This study offers a conceptual understanding of how a sample of women living within a culture considered privileged to possess 'a medically sanctioned' diet, subjectively experience food and eating.
\end{abstract}

Keywords: food, women, (in)security, subject experiences, Mediterranean diet

Introduction

Since the late 1960s, a great deal of nutritional research has been conducted on the Island of Crete. The Cretan diet has been the subject of study (longitudinal and cross-cultural) for decades now, and the changes in eating habits have been documented systematically (Aravanis, Corcodilas, Dontas, Lekos, \& Keys, 1970; Keys, 1997; Keys, et al., 1966). It is from those longitudinal studies that the "Mediterranean diet" phenomenon has come about, as has the study and interest in the consumption of olives and olive oil ('the elixir of life'). A team of researchers in 
Irakleio have documented the changes that have taken place in the Cretan diet and health (Kafatos \& Mamalakis, 1993; Mamalakis et al., 2006; Mamalakis, Kafatos, Manios, Anagnostopoulou, \& Apostolaki, 2000). Their research has documented that Greek children have been found to be the heaviest amongst their European counterparts, their fat intake has increased, and that the cardiovascular health of adults has declined among other findings (Mamalakis, et al., 2006; Mamalakis et al., 2000). The research of the Keys' and Kafatos' teams has a nutrition-medical focus. Unfortunately there are no studies for the Greek population which focus on the psychological components of eating, how people process and 'digest' the 'proper nutrition' information that is often provided by both media and the scientific discourses.

Traditionally, in the international social science literature issues of food and eating are relegated mostly to problems and difficulties in eating behavior and self-image. The models used in understanding the underlying reasons of feeding difficulties are mostly interpersonal in nature (Attie \& Brooks-Gunn, 1992; Bruch, 1994; Minuchin, 1978). Researchers have also developed models that represent the complex interplay of several variables, including biological (Wethington, 2005), psychological (Bisogni, et al., 2007; Bisogni, Jastran, Shen, \& Devine, 2005; Blake, et al., 2009; Devine, 2005; Devine, Brunson, Jastran, \& Bisogni, 2006; Jastran, Bisogni, Sobal, Blake, \& Devine, 2009), and sociocultural (Counihan, 1999; Murcott, 1997). The impact of media and images on eating behavior and eating disorders have also been emphasized (Richins, 1991; Striegel-Moore, Silberstein, \& Rodin, 1986; Williamson, 1990).

More specifically, issues of gender, body image and eating behavior have been studied and reviewed at length and across cultures (Jastran, et al., 2009). A life course framework has been applied in studying women's perceptions of how they change their food practices and preferences through time, due to social and lifestyle changes (Bisogni, et al., 2007; Devine, 2005; Edstrom \& Devine, 2001; Wethington, 2005). The question of why people eat as they do has been addressed from multiple perspectives such as identity (including ethnic), gender, employment status (Bisogni, Connors, Devine, \& Sobal, 2002; Bisogni et al., 2007; Bisogni, et al., 2005; Devine, Sobal, Bisogni, \& Connors, 1999; Montepare, 2007). Other studies focus on food preparation, family roles and time constraints which influence people's eating habits and behaviors (Blake et al., 2009; Devine, Connors, Sobal, \& Bisogni, 2003; Devine et al., 2006; Murcott, 1997).

Hence, studies in the social sciences have traditionally dealt both with problems in eating and feeding behavior, and therapeutic interventions put forth to alleviate 
such problems and many normative dimensions of eating and feeding one's family. More recently, there has been a focus in the counselling psychology and women's studies literature on the social construction of eating patterns, body consciousness and body image concerns (Choate, 2005; Hesse-Biber, 2007; Hesse-Biber, Leavy, Quinn \& Zoino, 2006; Montepare, 2007; Piran, 2010; Piran \& Cormier, 2005; Tindall, Robinson, \& Kagan 2010). The social science literature does allow one to surmise that interpersonal processes shape a person's self-image and body image, and concomitantly, the person's self-image, body image and representations prompt particular eating behaviors (Counihan, 1999). It is difficult to generalize the findings and conclusions of this large body of research to Crete because there has been such long-standing 'scientific' acclaim for the 'Cretan diet' and its health benefits.

The 'Mediterranean diet' has been a consistent part of the food practices of the Cretan population and a stable 'diet recommendation' of the medical establishment. The Island's population has not felt 'pressured' to change their food choices due to the medical discourses and recommendations on what is right and good to eat. Yet, the biologically based studies of the Cretan population cited above point to major changes in the biological markers which are the interface between food and health (Kafatos \& Mamalakis 1993; Mamalakis, et al., 2006; Mamalakis, et al., 2000). Community culture has been changing steadily on Crete and the traditional long-standing patterns of thought and behavior regarding food that were once transmitted intergenerationally through child-rearing, ceremonies, religious rituals and the structure of community institutions have been broadened to include the impact of the media, telecommunications, globalization and immigration (Kruobrysanakis, 2006).

Many questions as to how these changes have impacted human subjectivity with regard to food and eating behavior have remained unanswered. One's perceptions, experiences and interpretations of the world result from processing the social relationships and power differentials in which he or she is embedded (Ellis \& Flaherty, 1992). According to Bell (2002) subjectivity includes a person's experiences, perceptions and sensations as they are determined by semiotic (including linguistic) distinctions that are habitual to the person (p. 202). He states, "subjectivity can mean the 'subjective realm' - the realm of all the perception-events and semiotic events (including utterances) to which the personal pronouns 'I' and 'we' are or could be applied" (p.203). Subjectivity relates to the participants' perceptions, thoughts, beliefs, feelings and strategies related to food, nutrition and diet. In this inquiry, women's 'subjectivity' has more of a focus on how women's food practices are bound up in tier sense of self, such as 'who am l' and how that is constituted by the norms and discourses embedded in their social environment. This implies the 
adoption of a theoretical framework which acknowledges that food is culturally defined and acquires great significance in all cultural settings because it involves the body and is, in essence, an expression of embodiment.

The Cretan population provides the researcher with a unique opportunity to study how in the face of stable medical discourses regarding nutrition people change their traditional food orientations, practices, and perceptions. In order to explore and document Cretan women's subjectivity regarding food, diet, nutrition and the prevailing discourses on food, a community group that functions as a discussion and reflection forum on social issues in the Municipality of Rethymno discussed food, eating behavior and experiences of food insecurity. This paper will present how Cretan women experience food and will focus on the dynamics of food, subjectivity and (in)security within this particular community and the implications of this to counselling psychology.

\section{Methods}

Research questions and their significance

From the review of the literature cited above it is obvious that food has been studied extensively on Crete but not from the perspective of people's perceptions, feelings, habits and practices. Although, there is evidence of change in eating habits and health outcomes, the question of how Crete's inhabitants deal socially and emotionally with both change and all the divergent information about food, nutrition, and diet has remained unaddressed. This study posed the following questions as a path to addressing these issues:

- How do Cretan women describe their relationship to food, nutrition, and eating behavior?

- What are the connections and relationships between food and (in)security?

- What is the impact of Cretan women's habits, thoughts, practices and emotional reactions on how they experience their bodies?

This mode of inquiry is considered important given the call in the counselling psychology literature to focus on inner subjective experience (Hansen, 2005; Hansen, 2010; Rudes \& Guterman, 2007) as a means to intervene effectively and bring about change. 


\section{Context}

For the past 25 years or so, the Lyceum for Women in the town of Rethymno has been running an "educational group" as part of their wider program which aims to uphold Greek traditions and culture and to bolster the institution that is the bedrock of Greek cultural existence, the family. The "Lyceum for Women" is a non-profit organization that is considered a learning environment in the greater Rethymno Prefecture. The learning environment "Lyceum" has evolved from the belief that knowledge and culture are inextricably intertwined, that knowledge is created through the interaction of people in a relational community, and that learning by doing will bring about personal and communal change. Until recently, the group was psycho-educational in nature and consisted of lecture presentations in areas such as child development and parenting. The programming for the family currently entails an experiential and reflective format, with a focus on the family, its members as individuals and as members of the wider social and communal system. The theme for the lyceum group last year was food and subjectivity. It is important to note that several "food scares" coincided with the timing of the group. There were concerns about: avian flu (media warnings led to a very large drop in the consumption of poultry products and villagers who had raised their own chickens were by law forced to change their practices), trans-fats and 'fat', and the safety of beef consumption (i.e. mad cow and hoof and mouth diseases).

Participants and format of participation

As many as 65 people attended the open group community meetings with an average of 43 people on a regular basis. The participants were women and ranged in age from 20 to 85 years. The educational levels of the participants varied, as most participants had a high school education and at least one-third had completed university degrees. All of the participants prepared food at home on a daily basis. They were all people who live in Rethymno, of Greek heritage, who voluntarily participated in the research and who gave written informed consent.

Table 1 presents the themes, format, and issues for discussion, and experiential activities that constituted the agenda of the group. As shown in Table 1, the group discussions and activities were based on open-ended questions that attempted to enrich the unfolding process and to help the participants reflect upon their experiences, emotional and bodily reactions, and on communal aspects of their being with regard to food and eating. The group facilitator led the discussion which lasted for two hours each meeting. 
Table 1: Program themes and experiential activities for the 11-week community reflective practice intervention

Theme 1: What is my relationship to food, eating, diet, and nutrition?

Theme 2: How is food the object and the intersection between our body, our health, our mind and our behavior?

Activity: Food and my body image, my representations (collage, photos, drawings, and narratives)

Theme 3: Our diet: Is it nutritional or (and) does it make us sick?

Activity: Bring in articles and published information regarding health and diet. Discuss: how the media coverage of illness, diet, and eating behavior affects me?

Theme 4: How do social factors impact upon my eating behavior and practices?

Activity: Write down all the ways in which these controversies are embedded in your experience of your body: Do all the controversies around food affect by behavior? How? Let us role-play!

Theme 5: My childhood memories about food and eating: How do they affect my behavior, emotions, and self-body-concept?

Activity Telling stories around the dinner table. Let us dramatize them.

Theme 6: How is our consciousness constructed around body-image and eating behavior?

Activity: Intergenerational impact upon my body, let me draw it!

Theme 7: What are the-interpersonal foundations of body-image, body dysphoria, and eating behavior?

Activity Drama and the Greek chorus.

Theme 8: Sharing stories from our dinner table: What understandings do we derive from them?

Activity: A collective account of the media and the dinner table.

Theme 9: Food, tradition and our cultural heritage: How do these stories affect me and my eating behavior?

Activity: Old but not forgotten recipes: Let us share our creations.

Theme 10: Food, tradition and our cultural heritage: How do these stories affect me and my eating behavior?

Activity: The Cretan diet, traditions, research findings in press, how do I consume and reproduce these readings and understandings? Let us make a collage!

Theme 11: Food and (in)security some conclusions What are our conclusions regarding food, our body and our sense of (in)security?

Experiential activities and a reflective practice approach to communal dialogues was applied as a method of helping the group participants process and think critically about their experiences in a way that builds insight and awareness so that group participants increase their choices in the actions they take (Heron, 1996; 
Jaques, 1991; Kolb, 1984). In these activities, the construction and generation of meanings and understandings comes about through dialogue and critical reflection, processes which are relational in nature (Heron, 1996; Postle, 1993; Silberman, 2007). Learning and transformation are made possible by: (a) commitment to goals the participants have been involved in setting, (b) participation is appreciated and valued, and (c) a supportive community context (Heron, 1996; Jaques, 1991; Kagan, Tindall, \& Robinson, 2010; Kolb, 1984; Postle, 1993; Silberman, 2007).

These critical dialogues had the goal of developing 'shared understandings' of how food, nutrition, and eating behavior impact this community groups' subjectivities. The group coordinator was not an outsider to the group and she applied a non-authority stance in discussing and processing the themes and experiential activities. Her role was that of a resource person and facilitator and less of a 'psychologist' who had privileged information to share. It is important to note that in counselling psychology eating disorder intervention literature there has been a focus on community participatory approaches (Becker, Stice, Shaw, \& Woda, 2009; Becker, Smith, \& Ciao 2006; Levitt, 2004; Choate \& Schwitzer, 2009; Piran, 2010; Wilson, et al.,2010; Yager \& O'Dea, 2008). These authors call for empowerment counselling that includes education, media literacy, activism, transforming the social environment, engagement in critical dialogues and analysis of dissonance and systemic changes. These community counselling and prevention authors advise that eating behavior (including eating problems) do not develop in a vacuum but in a community environment that nourishes them, and hence, the processes of change have to be applied in the community context. This type of change can take place when community strengths are built upon, networks of connections are fostered, researcher-community member partnerships are forged and when co-learning and capacity building are encouraged (Becker, et al., 2009; Choate, 2005; Choate \& Schwitzer, 2009; Kagan, et al., 2010).

Method and approach to the analysis.

At the end of each session the participants summarized what remained with them of the process and the activities. An open ended questionnaire was given to them at the end of each session. They were given 15 minutes to answer as fully as possible the three questions and to provide the following demographic information, including: age, gender, educational background, marital status, family members living at home, and how often meals are cooked at home. The participants were assured that their answers would remain anonymous. 
The questionnaire consisted of the following three questions:

- How is the topic discussed in the group today connected to you and your experiences of food, eating, and nutrition?

- How is the topic discussed in the group today connected to your feelings and how you experience your body?

- What made the experiential activity we completed today meaningful for you?

These questions were addressed in an open-ended essay format and each participant completed approximately a half page of written narrative feedback. A total number of 452 reflective statements were collected and analyzed. A twophase process of feedback analysis was implemented after all eleven group sessions were completed. In the first phase of analysis, the written feedback was read by the researcher and an independent psychologist in order to glean the overriding themes that emerged from each session. The two psychologists participated separately at first in the analysis of emerging themes and then jointly in five 2-hour meetings where they both converged to ensure satisfaction with the classifications of the data. The data analysis involved reflecting on the responses, reading the transcripts, active construction of interpretations of the women's experiences, questioning of how these interpretations came about and outlining the dynamic relations between the realities the participants voiced and the psychological knowledge of what these accounts refer to (Bott, 2010). Data analysis followed an Interpretive Phenomenological Analysis approach (Smith \& Osborn, 2008) and included the following procedures: 1) classification of the data on worksheets according to the age, marital status and the number of prepared meals at home per week, 2) detailed thematic analysis of the reflective statements that the participants' completed for each session by the two psychologists until no new categories can be found per session, and 3) detailed verification of emerging themes by age, marital status, family members living at home and number of meals prepared at home. There was only one participant who was divorced, three who were not married and two who were widowed; hence this dimension could not be studied in detail. The number of family members living at home and the meals cooked at home per week did not reveal any clear patterns. The age dimension did reveal clear differences in how the women described their perceptions, feelings, and lived experiences of food. The age groups differences were verified and agreed upon by both psychologists and there were no negative cases related to age.

In the second phase of analysis the participants' responses were studied, coded and clustered by the researcher and the independent psychologist in order to reach a consensus as to how subjectivity is impacted upon by the food discourses that have permeated the community. Moreover, the two psychologists analyzed and clustered 
the emerging themes that touch upon the role of emotions and how these feelings are embodied. The participants' written narratives were first read by the researcher who made a list of all references to feelings such as worry, fear, being scared, insecure, secure, safe, unsafe, anxiety, and embodiment (bodily-felt sense). From this analysis the thematic categories that emerged were: food-emotional reactions; food-eating behavior; and food-embodiment. The written narratives were then coded by the independent psychologist whose task was to cross-check the original written narratives and the categories that emerged in order to verify the connections narrated by the participants between food, eating behavior, nutritional knowledge/ information, (in)security and embodiment.

\section{Results}

This first phase of analysis revealed that there were differences in focus regarding food, diet, nutrition and worry and (in)security according to the age groups of the participants. The participants who belonged to the age group from 20 to 35 (approximately 8 women each session) focused more on worry and concern regarding body image, diet, and maintaining an 'appealing' body size. Food for this age group is viewed as a 'חعוpaouós' (temptation)-that is something that is tempting and that places one in an awkward position of having to deal with temptation.

The participants belonging to the age group from 35 to 50 (approximately 20 women each session) focused primarily on fears or confusion about proper nutrition, media messages, and preparing nutritious food for their families. This sub-group also mentioned the decline in the frequency of family meals and traditional norms for eating. Food for this group of participants is a word imbued with conflict-one participant stated-"There is a tug of war that goes on in my house regarding food, what should we be eating, what the kids want, what is good for us, what are the "bad' foods-it is too much."

The participants who were in the 50 to 85 -years-old age range (approximately 10 women each session) focused mostly on diet and nutrition that is medically related, for example, eating the 'right foods' for medical problems such as high cholesterol. Participants from this age group also underscored their worries and ambivalence about the social and cultural changes that have contributed to the demise of local cuisine, eating traditions, and to the respect toward the collective rhythms that Greek Orthodox religion dictates in eating, fasting, and preparing food. They also 
viewed food as something 'sacred' that should not be wasted and that people should feel grateful for having enough to eat.

In summary, this phase of the analysis revealed that Cretan women of varying ages are concerned about food, eating and their bodies but in different ways. The international literature has brought forth numerous contradictions of concerning women's experiences and concerns and eating behavior across the lifespan (Johnston, Reilly \& Kremer, 2004)). The results from this analysis highlight the complexity of the relationship between age, eating behavior and concern about one's body. All age groups voiced concern and insecurity regarding eating and their bodies, however, with age changing priorities amplify social awareness and a concern for healthiness in diet and how one eats and controls their eating.

The second phase of analysis consisted of a more 'in-depth' analysis in order to delineate how the participants connected the food topic discussed during each session to emotional subjectivity, and from the participants' perspectives what interplay of factors contribute to food (in)security and how this is embodied. The feedback of the group participants revealed the following categories: foodemotional reactions, food-eating behavior, and food-embodiment.

In the food-emotional reactions outcomes the participants narrated the following:

- "Diet is the scary word; it is associated with 'experts', "do's and don'ts", control of food intake, "bad and good foods", and with a thin body image."

- "More than anything we fear fat today, getting fat, eating fats, and fear of looking bad because fat is bad."

- "Because we worry about fat, we feel guilty about eating certain foods."

- "Food can be bad for our health, food can be fattening, and food is always on our mind when we diet, when we overeat, and when we eat the wrong things. All these things make me worry, feel guilty and stressed about food."

- "I often feel ambivalent about food...questions that come to mind are: is it good for me, can I afford the calories, is it easy to prepare, will the kids eat this or will my efforts go to waste?"

The mothers of children and adolescents regarded food as a subject of concern because they felt it had significant implications for their children's health: key aspects of this were their perceived need to "encourage children to eat fresh fruit and vegetables," concerns about children consuming "fast food" and the risk of them growing up "overweight" or having high cholesterol. Other mothers focused on the stress of cooking carefully prepared and traditional home cooked meals on a daily basis. As a group they stressed the confusion that exists and is engendered 
within them in all the media messages and older and persistent cultural dispositions about food. They mentioned the personal turmoil in making the right choices each day and the interpersonal tensions in "getting children to eat the right things." The women who worked and had no help from their extended families expressed more anxiety and pressure due to time constraints. Different aspects of these women's psychosocial identities (i.e. Cretan, mother, woman who works out of the home, woman who is in charge of cooking) are impacted upon their thoughts, feelings, and perceptions about food and eating (Bisogni, et al., 2002).

Along similar lines in the food and eating behavior outcomes, there was a focus on what is the 'right' knowledge and information and how difficult it is to act according to all the discourses that prevail. One participant wrote: "Now that there is a plethora of foods available, we do not know what to eat." There was also an emphasis on the communal/ interpersonal aspects of eating: "Yes, what we eat is important, but how we eat is also important, that is sitting around the table to enjoy our food, otherwise it will come out of our nose." And, more poignantly, "These days we consume food, information, even each other, consumption is a way of being and relating today." Once again parents mentioned the impact of media: "The table where our family gathers to share food is now a place where the television blares in the background, it influences us more than our conversations. The reporters' messages on what is right and wrong to eat affect our every bite." The participants emphasized the impact of socially imposed change in their ways of relating to food and to each other, something that is highlighted in the international literature (Bisogni, et al., 2002; Bisogni, et al. 2007; Devine, 2005).

The food-embodiment outcomes were a bit more difficult to decipher yet they were very telling. One participant wrote, "Our bodies have become war zones; we are constantly dieting and fighting fat." Another participant analyzed embodiment in the following fashion,

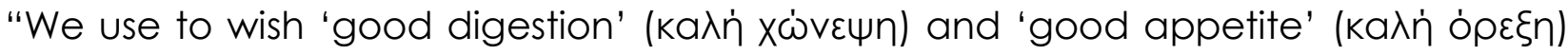
to each other in my family of origin, in my home today the last thing we think about is digestion, we often forget that how our body processes food is important. How we feel about the food we eat is related to how well we digest it, if we fear or do not find it appetizing... how can digestion go well?"

Others mentioned the following in their feedback:

- "I am the type of woman who wants to rebel against the prevailing images in the media about women's bodies, yet when I look into the mirror I view my body through the lens of those images." 
- "I have caught myself saying to my children, 'that will make you sick, that causes cancer,' what does this do to them?"

- "Too many food scares are spoiling our appetites, as are diets and obsession with body image."

- "A lot of talk in the media today makes the food we swallow get stuck in our throats.... That is I often do not eat with an appetite, I am often ambivalent about what is on my plate."

- "Each day I experience a great deal of stress around food-the anxiety of making choices, the fatigue of all the preparation, a horrible knot in my stomach that is the result of knowing what religious or local traditions dictate on the one hand and what I am doing on the other... no wonder digestion is a problem for me."

In summary, the voices of this group of Cretan women describe their relationship to food and eating as complicated and fraught with ambiguities and insecurities. Moreover, they highlight how their thoughts and emotional reactions impact upon their bodies, sense of control, and experiences of eating. They state emphatically that eating should be a pleasurable personal and interpersonal endeavor and that in today's pressure-filled and media-constructed world it no longer is. The media and other social discourses appear to be disempowering according to the women of this study.

Embodiment was perceived and underscored differently for the three age groups. The younger participants expressed more worry and concern about body-image, body size, and fear of fat. This younger sub-group of participants appeared to have succumbed to more recent sociocultural pressures about body image, having internalized the 'thin-ideal' which prevails in the media. The 35 to 50 year olds seemed to be more focused on the confusion that divergent scientific information about nutritious, healthy, and both diet permitted and 'safe' created for them. Several people from this age group also mentioned being forced to eat all their food when they were young and being overfed sometimes by their mothers or grandmothers. They interpreted these behaviors as having to do with the 'occupation syndrome'-the WWII and its aftermath years where many families did not have enough to eat and where most families had very little choice as to what was available to eat. This according to the participants created an 'obsession' with food, a constant worry if their family/ children are eating enough to grow and be healthy. For the older participants, embodiment was linked to medically related illness and diet and also to the 'occupation syndrome.' Many of the people from this older group remembered craving certain foods, feeling deprived of them, and having eaten too much of other foods, and thus, disliking them now. These 
experiences have perhaps led this sub-group of participants not to endorse the currently prevailing societal beliefs about thinness, suggesting that sociocultural norms, practices, and pressures, can be assimilated or internalized into one's sense of self and subjectivity to varying degrees. In this instance, it appears that it is not that these women feel that they are active agents or fully self-determined in not internalizing these new pressures. The pressing presence of past traditions and experiences and the not-forgotten historical events, cultural eating habits and the 'scientifically privileged' Cretan diet appear to be in an internal and bodily felt tugof-war with the new discourses and sociocultural eating habits.

The older participants focused more on the constant change in food production, preparation and eating habits. One mentioned, "During the war years the common problem was finding food, now our minds, bodies, and souls suffer by not thinking of the needy, buying too much, consuming too much and obsessing too much about what to eat!" Others of this older age group focused on the Cretan diet, celebrations, changes in food production and how there is "loss of local traditions." They mentioned that there is a "paradox in that the Mediterranean diet is no longer being consumed in its birth place." The fact that people do not produce their own foods and may not even prepare them was also pointed out by this age group. The loss of cooking traditions, hospitality and sharing were also apparent in their written narratives. The demise of traditions such as fasting (not eating meat, its derivatives and fish) on Wednesdays and Fridays and other religious occasions that were part of the Greek Orthodox fasting protocol was also highlighted by this age group. One participant wrote: "Up until recently mostly everybody followed the fasting rituals, this was good for our health, it was a way to avoid cholesterol and to become disciplined about eating, but very few people do that today." Viewing food as sacred and not something to be wasted was also part of these 'traditions'.

\section{Discussion and conclusion}

The participants in this reflective research endeavor were most willing to talk, process, and narrate in written format their concerns, understandings, memories, worries, and confusion concerning diet, nutrition, and media and scientific messages centering on food. The results of the narrative reflective feedback analysis indicate that there was a different emphasis on concerns and worries about food according to age cohort groups with the younger group attendees being aware that their concerns center mostly on body-image, fatty foods consumption, and diet, the middle age group focusing on worries about their children's health and diet, and the older age group focusing on health issues and the loss of traditional food habits and 
rituals and the 'sacredness of' food eating and sharing. These findings coincide with the 'life course perspective' a framework for understanding how food choices, preferences, and patterns in eating are associated 'temporal, social, and historical' trajectories (Bisogni, et al., 2002; Bisogni, et al., 2005; Devine, 2005; Devine, Jastran, et al., 2006; Johnston, Reilly, \& Kremer, 2004; Wethington, 2005).

Traditionally, women on Crete had developed their eating habits, food preferences, and sense of identity by being acculturated into the social rules and ethos of their particular Cretan culture. The geography of the Island, the climate, the Greek Orthodox religious practices, the settlement history of the Island all influence the food production, preparation, cuisine and the embodiment of this particular culture by the Island's inhabitants. The food choices were traditionally what was locally grown and available and hence sanctioned as 'proper' to eat. "Cretan diet and cuisine" is an expression of their identity and a focal point of social activity, and concomitantly in the past 40 years, 'the superior diet,' 'the healthiest alternative' and 'medically sanctioned' cuisine.

Hence, in the Rethymno community context all three sub-groups of women had not experienced or been subjected to changing health/ diet policies and medical discourses regarding their traditional diet, yet it was only the older women sub-group that had remained very stable and persistent in their eating habits, their thoughts and feelings about diet and eating and the nature and the meaning of food in their lives. For the middle age sub-group the changing social context with regard to food and individual change (having a family, working outside the home, not having extended family supports) impacted their subjective experiences of food-- choices, preparation, concerns, and worries. This subgroup described in very vivid and distinct voices the tensions in managing time, making choices for their families and coping with the diverse food 'pressures' and 'tensions', echoing the literature on the time pressures, sacrifices and food choice and preparation challenges (Blake et al., 2009; Devine et al., 2006; Devine, et al., 1999).

It is interesting to underline that these women did not focus explicitly and at length on the pressures to follow traditional roles, food choices, habits, social markers and ceremonies, yet did express embodied tension, stress, and emotional turmoil. Perhaps in this manner they were expressing the entrapment they embody-feeling trapped between the old and new social context as it is emerging. These women's embodied subjective experiences highlight Bourdieu's discussion of 'habitus' and the 'hysteresis effect'--the tension between the formation of new cultural habits and dispositions and the pressing presence of those formed in the past (Bourdieu, 1984). 
The women described vividly this clash of the new and old habits and ways of being and their bodily-felt sense of powerlessness in reconciling or coming to terms with it.

The younger age group focused more persistently on body image relegating it to a social marker for personal and social identity, where a fit body was equated with being successful in dieting and self-control (Bisogni, et al., 2002). These women's words imply a body-management focus, the practices associated with it and the complex relationships with food and their bodies that they described were obviously a part of the normative discourses in the media and in the culture at large. These women were not 'anorexic' or 'bulimic' or otherwise 'eating disordered.' The implications of this finding are that such 'eating pathologies' are culturally embedded and hence not outright 'personal pathologies' (Choate \& Schwitzer, 2009; Hesse-Biber, 2007; Malson \& Swann, 1999; Piran, 2010; Piran \& Cormier, 2005).

Hence, a cultural clash was also a part of these women's embodied subjectivity in that they lived in two distinct worlds-the old of their parents and of local Cretan traditions, Cretan cuisine and socialization processes and the new 'lifestyle' world of the media focusing on the self-interest, bodily perfection and weight management practices. In essence this new world could be anywhere and these women embodied the pressures of being/living/ experiencing in a decontextualized and perhaps compartmentalized "social universe' devoid of place (Delind, 2006). The implications of this finding is that counselling professionals working in prevention or intervention of eating difficulties or in the public health domain need to take into consideration the complexities of social identity, embodiment, and habitus \{internalization of culture that guides food choices and eating habits\} (Heading, 2008; Hesse-Biber, 2007; Piran, 2010).

The women in the middle age group and the younger group, taken together voice clearly that traditional meal patterns and practices have changed a great deal. Their changing social roles and identities (e.g., work roles, the dictum 'we are what we eat'), family organization (from an extended family system to more of a nuclear family system), media messages and the greater availability of 'fast foods' and the availability of many food options have made family meals more hurried and fewer in number. This finding corresponds to the international literature (Bisogni, et al., 2002; Poulain, 2002) that describe the decline in the traditional norms for eating, preparing food, and sharing meals. For these women all this distressful in that in today's globalized Crete what they 'know' and have experienced and internalized through lived interpersonal interactions is somehow 'negated' or strongly influenced by the media, consumerism, telecommunications and the globalized world markets. In Bourdieu's terms embodiment becomes the focal point for understanding the lived 
meaning of a constantly changing culture-persistent expectations from the past and contemporary experiences (Bourdieu, 1984).

Further analysis revealed that the participants were very much aware of the pervasive role that food and food insecurity play in their lives. This finding coincides with anthropological studies of food and eating behavior (Mintz \& Du Bois, 2002). Cretan social life seems to be inextricably entwined with food and this was highlighted by the memories, stories, and concerns that the participants provided as feedback. Food and social change were mentioned in many of the feedback protocols and more detailed research is needed in order to capture how the dietary habits of Crete's inhabitants have been affected by the very present social change. Along this same line, the war years and insecurity about food during that time as compared to today is also ripe for interdisciplinary and psychological research. The phenomenon dubbed the 'occupation syndrome' by these participants appears to be an interesting interpretation and way of producing culturally relevant meaning. Eating and ritual and their relationship to identity were also touched upon by the participants and this has to be researched in a more in-depth fashion.

This small project touched upon the relation of food, subjectivity, (in)security and embodiment in the Cretan culture. The women voluntarily joined and attended the group and participated in the research and were very forthcoming with in-depth information of their subjective experiences of food and eating. The study focused solely on women's lives and experiences with food and a similar study needs to be conducted with Cretan men. This study offers conceptual understanding of how a sample of women living within a distinct culture, a culture considered privileged to possess 'a medically sanctioned' diet and cuisine, subjectively experience food and eating. This collaborative community research and intervention endeavor also highlights how inner subjective experience can be used in counselling towards building personal and community capacity via helping women discuss, reflect upon, and analyze their experiences. The women feel included and empowered by contributing to the social discourses and constructions. They also feel less alone with the ambiguities and socialcultural pressures that permeate their daily lives. Much remains to be done in exploring these issues in a more detailed and comprehensive way, it may be though, that the community partnership research and prevention methodology may be a sound one in that it allows people to collaborate, talk, debate and grapple with the realities of their changing communities, habits, behaviors, and health. 


\section{References}

Aravanis, C., Corcodilas, A., Dontas, A.S., Lekos, D., \& Keys, A. (1970). Coronary heart disease in seven countries, IX. The Greek islands of Crete and Corfu. Circulation, 41 (4 Suppl), 88-100.

Attie, I., \& Brooks-Gunn, J. (1992). Developmental problems in the study of eating problems and disorders. In J. H. Crowther, D. L. Tennenbaum, S.E. Hobfoll, \& M.A.P. Stephens (Eds.), The etiology of bulimia nervosa: The individual and familial context (pp. 35-58). Washington, DC: Hemisphere.

Becker, C. B., Smith, L. M., \& Ciao, A C. (2006). Peer-facilitated eating disorder prevention: a randomized effectiveness trial of cognitive dissonance and media advocacy. Journal of Counseling Psychology, 53, 550-555.

Becker, C. B., Stice, E., Shaw, H., \& Woda, S. (2009). Use of empirically-supported interventions for psychopathology: can the participatory approach move us beyond the research-to-practice gap? Behaviour Research and Therapy, 47, 265-274.

Bell, P. (2002). Subjectivity and identity: semiotics as psychological explanations. Social semiotics, 12, 201-217.

Bisogni, C. A., Connors, M., Devine, C., \& Sobal, J. (2002). Who we are and how we eat: a qualitative study of identities in food choice. Journal of Nutrition Education and Behavior, 34, 128-139.

Bisogni, C. A., Falk, L. W., Madore, E., Blake, C. E., Jastran, M., Sobal, J. \& Devine, C. M. (2007). Dimensions of everyday eating and drinking episodes. Appetite, 48, 218-231.

Bisogni, C. A., Jastran, M. Shen, L., \& Devine, C. M. (2005). A biographical study of food choice capacity standards, circumstances, and food management skills. Journal of nutrition education and behavior, 37, 284-291.

Blake, C. E., Devine, C. M., Wethington, E., Jastran, M., Farell, T. J., \& Bisogni, C. A. (2009). Employed parents' satisfaction with food-choice coping strategies. Influence of gender and structure. Appetite, 52, 703-710.

Bott, E. (2010). Favourites and others: reflexivity and the shaping of subjectivity and data in qualitative research. Qualitative research, 10, 154-173. 
Bruch, H. (1994). Conversations with anorexics: Compassionate and hopeful journey through the therapy process. NY: Jason Aronson.

Bourdieu, P. (1984). Distinction: a social critique of the judgment of taste. London: Routledge and Kegan Paul.

Choate, L. H. (2005). Toward a theoretical model of women's body image resilience. Journal of Counseling \& Development, 83, 320-330.

Choate, L. H., \& Schwitzer, A. M. (2009). Mental health counseling responses to eatingrelated concerns in young adult women: a prevention and treatment continuum. Journal of Mental Health Counseling, 31, 164-183.

Counihan, C. M. (1999). The anthropology of the body: Gender, meaning, and power. New York, NY: Routledge.

Delind, L.B. (2006). Of bodies, place, and culture: re-situating local food. Journal of Agricultural and environmental ethics, 19, 121-146.

Devine, C. M. (2005). A life course perspective understanding food choices in time, social location, and history. Journal of nutrition education and behavior, 37, 121-128.

Devine, C. M., Brunson, R., Jastran, M., \& Bisogni, C. (2006). It just really clicked participant-perceived outcomes of community nutrition education program. Journal of nutrition education and behavior, 38, 42-49.

Devine, C. M., Connors, M. M., Sobal, J., \& Bisogni, C. A. (2003). Sandwiching it in: spillover of work onto food choices and family roles in low- and moderate-income urban households. Social science and medicine, 56, 617-630.

Devine, C. M., Jastran, M., Jabs, J., Wethington, E., Farell, T. J., \& Bisogni, C.A. (2006). "A lot of sacrifices": work-family spillover and the food choice coping strategies of lowwage employed parents. Social science and medicine, 63, 2591-2603.

Devine, C. M., Sobal, J., Bisogni, C., \& Connors, M. (1999). Food choices in three ethnic groups: interactions of ideals, identities and roles. Journal of nutrition education, 31, 8693.

Edstrom, K. M., \& Devine, C. M. (2001). Consistency in women's orientations to food and nutrition in midlife and older age: a ten year qualitative follow-up. Journal of nutrition education and behavior, 33, 215-223. 
Ellis, C., \& Flaherty, M. (1992). Investigating Subjectivity. Newbury Park, CA: Sage.

Hansen, J. T. (2010). Inner subjective experiences and social constructionism: a response to Rudes and Guterman (2007). Journal of Counseling \& Development, 88, 210-213.

Hansen, J. T. (2005). The devaluation of inner subjective experiences by the counseling profession: a plea to reclaim the essence of the profession. Journal of Counseling \& Development, 83, 4-6-415.

Heading, G. (2008). Rural obesity, healthy weight and perceptions of risk: struggles, strategies and motivation for change. Australian journal of rural health, 16, 89-91.

Heron, J. (1996). Helping whole people learn. In D. Boud \& Miller, N. (Eds.), Working with experience: Animating learning (pp. 75 -91). London: Routledge.

Hesse-Biber, S. N. (2007). The cult of thinness, $2^{\text {nd }}$ edition. New York, NY: Oxford University Press.

Hesse-Biber, S., Leavy, P., Quinn, C. E., Zoino, J. (2006). The mass marketing of disordered eating and eating disorders: the social psychology of women, thinness and culture. Women's Studies International Forum, 29, 208-224.

Jaques, D. (1991). Learning in groups (2nd Ed.). London: Kogan Page.

Jastran, M. M., Bisogni, C. A., Sobal, J. Blake, C., \& Devine, C. M. (2009). Eating routines. Embedded, value based, modifiable, and reflective. Appetite, 52, 127-136.

Johnston, O., Reilly, J., \& Kremer, J. (2004). Women's experiences of appearance concern and body control across the lifespan: challenging accepted wisdom. Journal of health psychology, 9, 397-410.

Kafatos, A., \& Mamalakis, G. (1993). Changing patterns of fat intake in Crete. European Journal of Clinical Nutrition, 47, 685-692.

Kagan, C., Tindall, C., \& Robinson, J. (2010). Community psychology: linking the individual with the community. In R. Woolfe, S. Strawbridge, B. Douglass \& W. Dryden (Eds.), Handbook of Counselling Psychology, $3^{\text {rd }}$ Edition (pp. 485-504). London: Sage publications.

Keys, A. (1997). Coronary heart disease in seven countries. 1970. Nutrition, 13, 250-252. 
Keys, A. (1980). Wine, garlic, and CHD in seven countries. Lancet, 1 (8160), 145-1 46.

Keys, A., Aravanis, C., Blackburn, H.W., Van Buckmem, F. S., Buzina, R., Djordjevic, B.D., Dontas, A.S.,....Taylor, H. L. (1966). Epidemiological studies related to coronary heart disease: characteristics of men aged 40-59 in seven countries. Acta Medica Scandinavia Supplement, 460, 1- 392.

Kolb, D. (1984). Experiential learning. Engelwood Cliffs, N J: Prentice Hall.

Kruobrysanakis, L. K. (2006). Panorama Rethymno (All about Rethymno). Crete: Graphotechniki of Crete.

Levitt, D. H. (2004). Drive for thinness and fear of fat among college women: implications for practice and assessment. Journal of college counseling, 7, 109-117.

Malson, H., \& Swann, C. (1999). Prepared for consumption: (Dis)orders of eating and embodiment. Journal of community and applied social psychology, 9, 397-405.

Mamalakis, G., Jansen, E., Cremers, H., Kiriakakis, M., Tsibinos, G., \& Kafatos, A. (2006). Depression and adipose and serum cholesteryl ester polysuturated fatty acids in the survivors of the seven countries study population of Crete. European Journal of Clinical Nutrition, 60, 1016-1023.

Mamalakis, G., Kafatos, A., Manios, Y., Anagnostopoulou, T., \& Apostolaki, I. (2000). Obesity indices in a group of primary school children in Crete: A six year prospective study. International Journal of Obesity, 24, 765-771.

Mintz, S. W., \& Du Bois, C. M. (2002). The anthropology of food and eating. Annual Review of Anthropology, 31, 99-119.

Minuchin, S. (1978). Psychosomatic families: Anorexia nervosa in context. MA: Harvard University Press.

Montepare, J. M. (2006). Body consciousness across the adult years: Variations with actual and subjective age. Journal of adult development, 13, 102-107.

Murcott, A. (1997). Family meals-a thing of the past. In P. Caplan (Ed.), Food, health and identity (32-49). London: Routledge.

Piran, N. (2010). A feminist perspective on risk factor research and on the prevention of eating disorders. Eating Disorders, 18, 183-193. 
Piran, N., \& Cormier, H. C. (2005). The social construction of women and disordered eating patterns. Journal of Counseling Psychology, 52, 549-558.

Postle, D. (1993). Putting the heart back in learning. In D. Boud, R. Cohen, \& D. Walker (Eds.), Using experience for learning (pp. 33 -45). Buckingham: The Society for Research into Higher Education \& Open University Press.

Poulain, J.P. (2002). The contemporary diet in France: "de-structuration' or from commensalism to "vagabond feeding". Appetite, 39, 43-55.

Richins, M. A. (1991). Social comparison and the idealized images of advertising. Journal of Consumer Research, 18, 71-83.

Silberaman, M. (2007). Changing attitudes and behaviours through experiential activity. In M. Silberman, (Ed.). The handbook of experiential learning (pp. 13-32). CA: Pfeiffer.

Smith, J. A., \& Osborn, M. (2008). Interpretive phenomenological analysis. In J. Smith (Ed), Qualitative psychology (pp. 53-80). London: Sage.

Striegel-Moore, R. H., Silberstein, L. R., \& Rodin, J. (1986). Toward an understanding of risk factors for bulimia. American Psychologist, 41, 246-263.

Tindall, C., Robisnon, J., \& Kagan, C. (2007). Feminist perspectives. In R. Woolfe, S. Strawbridge, B. Douglass \& W. Dryden (Eds.), Handbook of Counselling Psychology, 3rd Edition (pp. 213-234). London: Sage publications.

Wethington, E. (2005). An overview of the life course perspective: implications for health and nutrition. Journal of nutrition education and behaviour, 37, 115-120.

Williamson, D. A. (1990). Assessment of eating disorders: Obesity, anorexia, and bulimia nervosa. Elmsford, NY: Pergamon Press.

Wilson, D. B., Johnson, R. R., Jones, R. M., Krist, A H., Woolf, S. H., \& Flores, S. K. (2010). Patient weight counseling choices and outcomes following a primary care and community collaborative intervention. Patient Education \& Counseling, 79, 338-343.

Yager, Z., \& O'Dea, J. A. (2008). Prevention programs for body image and eating disorders on University campuses: a review of large, controlled interventions. Health Promotion International, 23, 173-189. 


\section{About the author:}

Sofia Triliva is an Assistant Professor in the Department of Psychology at the University of Crete. Her primary are of research is the development and empirical validation of mental health prevention programming and mental health promotion initiatives for children, families and communities.

Address for correspondence: Sofia Triliva, Department of Psychology, University of Crete, 74100, Gallos, Rethymnon, Greece.

E-mail: triliva@psy.soc.voc.gr 